\title{
The effect of motivational interviewing on glycaemic control and perceived competence of diabetes self-management in patients with type 1 and type 2 diabetes mellitus after attending a group education programme: a randomised controlled trial
}

\author{
L. K. Rosenbek Minet • L. Wagner • E. M. Lonvig • \\ J. Hjelmborg • J. E. Henriksen
}

Received: 25 August 2010 /Accepted: 17 February 2011/Published online: 1 April 2011

(C) Springer-Verlag 2011

\begin{abstract}
Aims/hypothesis The aim of this study was to measure the efficacy of motivational interviewing (MI) compared with usual care on changes in glycaemic control and competence of diabetes self-management in patients with diabetes mellitus.
\end{abstract}

Electronic supplementary material The online version of this article (doi:10.1007/s00125-011-2120-x) contains supplementary material, which is available to authorised users.

L. K. Rosenbek Minet $(\bowtie) \cdot$ J. E. Henriksen

Department of Endocrinology M, Odense University Hospital and Institute of Clinical Research, Faculty of Health Sciences, University of Southern Denmark,

Odense, Denmark

e-mail: lisbeth.minet@ouh.regionsyddanmark.dk

L. Wagner

Research Unit of Nursing, Institute of Clinical Research, Faculty of Health Sciences, University of Southern Denmark, Odense, Denmark

E. M. Lønvig

Department of Quality, Odense University Hospital,

Odense, Denmark

\section{K. Rosenbek Minet}

Department of Rehabilitation, Odense University Hospital and Institute of Clinic Research, Faculty of Health Sciences, University of Southern Denmark,

Sdr. Boulevard 29,

5000 Odense C, Denmark

J. Hjelmborg

Department of Biostatistics, University of Southern Denmark,

Odense, Denmark
Methods Patients were eligible if they had type 1 or 2 diabetes mellitus, were over 18 years of age and had participated in a 4 day group education programme offered at a diabetes clinic at a university hospital in Denmark. Exclusion criteria included pregnancy, severe debilitating disease and cognitive deficit. Out of 469 patients who attended the group education programme, 349 patients were randomised to either a usual care control group or an intervention group, which received up to five individual counselling sessions in 1 year based on MI, in addition to usual care. A randomised parallel design was used and openlabel allocation was done by random permuted blocks, with allocation concealment by sequentially numbered, sealed, opaque envelopes. The primary outcome was glycated haemoglobin $\left(\mathrm{HbA}_{1 \mathrm{c}}\right)$. Analysis regarding measurements of glycated haemoglobin $\left(\mathrm{HbA}_{1 \mathrm{c}}\right)$ and competence of selfmanagement (using the Problem Areas in Diabetes Scale [PAID] and Perceived Competence for Diabetes Scale [PCDS]) was based on 298 participants followed for a 24 month period. Data were collected at the Department of Endocrinology at Odense University Hospital. Our hypotheses were that MI could: (1) reduce $\mathrm{HbA}_{1 \mathrm{c}}$ levels; (2) increase self-efficacy; and (3) increase diabetes self-care, compared with usual care.

Results Out of the 176 included in the control group and 173 in the intervention group, 153 and 145 were analysed in the groups, respectively. When using the baseline value as covariate there were no significant differences in change score between the two study groups with regard to mean level of $\mathrm{HbA}_{1 \mathrm{c}}(0.131, p=0.221)$, PAID scores $(-1.793$, $p=0.191)$ or PCDS scores $(0.017, p=0.903)$ at the 24 month follow-up, using a mixed effects regression model. The 
patients in the intervention group showed significantly higher levels of perceived competence in dealing with diabetes compared with the control group (mean change score $=-0.387, p=0.002$ ) following 1 year of intervention. Conclusion/interpretation We were unable to demonstrate any benefit, over or above usual care, of MI in patients with diabetes who have just completed a diabetes education programme, and who have well-regulated diabetes.

\section{Trial registration Clinical Trials NCT00555854.}

Funding The National Board of Health, Funen County, Danish Association of Diabetes, Odense University Hospital, University of Southern Denmark and TRYG Fonden.

Keywords Clinical trial · Diabetes mellitus · Motivation . Patient education $\cdot$ Self care

$\begin{array}{ll}\text { Abbreviations } \\ \text { MI } & \text { Motivational interviewing } \\ \text { MITI } & \text { Motivational Interviewing Treatment Integrity } \\ \text { OHA } & \text { Oral hypoglycaemic agents } \\ \text { PAID } & \text { Problem Areas in Diabetes } \\ \text { PCDS } & \text { Perceived Competence for Diabetes Scale }\end{array}$

\section{Introduction}

Self-management of diabetes requires that patients are able to reconcile their resources and preferences with the therapeutic regimen of diabetes, which can be a challenging task for many patients $[1,2]$. It has been widely accepted that diabetes education is not only required in the first few months following diagnosis but is an important component of ongoing diabetes care because of the onerous requirements for self-care that demand multiple daily decisions in order to balance diet, physical activity and medications [3]. There has been a keen interest in examining the impact of different kinds of patient education programmes on diabetes self-management. The findings of several meta-analyses of randomised controlled trials provide extensive evidence for the effectiveness of behavioural and educational intervention on fasting blood glucose and glycated haemoglobin, but the long-term effects of such interventions are uncertain [4-8]. Knowledge about the effectiveness of behavioural and educational intervention on other diabetes-related outcome measures, including blood pressure, lipid profile, body weight, self-management skills, health behaviour and psychosocial aspects, is less clear [3, 9, 10]. Critical assessment of the impact of behavioural and educational programmes requires further research based on rigorous methods in high quality studies with a large number of participants, long-term follow-up on effectiveness and welldefined interventions [9-11].
Motivational interviewing (MI), defined by Rollnick and Miller, is a well-defined and scientifically tested method of client counselling that has successfully been used to elicit and sustain a person's behaviour changes in a number of healthcare areas [12]. A recent review of MI showed improvements in health behaviour (e.g. diet and exercise) in patients with diabetes [13]. Research has not yet been able to establish full consensus on the effect of MI on clinical [14-19] and psychosocial aspects [15, 18, 20-22] in diabetes. Previous reviews emphasise the need for studies of high methodological quality and adequate power to explore the effect of MI on glycaemic control and wellbeing in patients with diabetes $[11,13,23]$.

In this study, we explored the significance of supporting patients with diabetes to manage their diabetes over time. The aim was to study the effect of a 1-year intervention programme based on MI following a group education programme on glycaemic control and competence of management in patients diagnosed with type 1 or type 2 diabetes mellitus. Our hypotheses were that, in a sample of people who have just completed a group education programme, a course of motivational intervention following group education could: (1) reduce $\mathrm{HbA}_{1 \mathrm{c}}$ levels; (2) increase self efficacy; and (3) increase diabetes self-care, compared with usual care.

\section{Method}

Research settings

This study was conducted at a diabetes clinic, located within a university hospital in Denmark with an intake of patients from both urban and rural areas in the region. The hospital is a local hospital with an intake area that reflects other hospital intake areas in Denmark. Patients can be referred by their general practitioner or other hospital departments to the diabetes clinic. At the clinic, patients are offered ongoing individual counselling by dietitians, nurses or physicians and group education delivered by a multidisciplinary healthcare team over 4 days. The 4 day diabetes education programme includes approximately eight to ten patients and focuses on a range of themes such as diabetes treatment, prevention of diabetes-related complications, self-monitoring of blood glucose, diet, physical activity, alcohol use and issues regarding insurance. The teaching method is based on guided self-determination designed to guide patients and professionals in mutual problem-solving [24].

Research participants and design

Patients were eligible if they had type 1 or type 2 diabetes mellitus, were over 18 years of age and had participated in 
the group education programme offered at the diabetes clinic. Exclusion criteria included pregnancy, severe debilitating disease and cognitive deficit. The patients were informed at day 1 and recruited at day 4 while participating in the group education programme. Following informed consent, the patients were randomised to either a control group or an intervention group. Randomisation was done immediately after participation in the group education programme. No stratification was used. All outcome measures were assessed at randomisation, 1 and 2 years after randomisation in both groups. Randomisation was generated by random permuted blocks, with allocation concealment by sequentially numbered, sealed, opaque envelopes. The person generating the allocation scheme did not administer the allocation of the patients to the two groups and was not part of the research team.

The sample size was determined by a power calculation. With 352 patients, 176 in each group, the trial can detect a $0.4 \%$ difference in $\mathrm{HbA}_{1 \mathrm{c}}$. The power was set to $90 \%$. This calculation was based on a standard deviation of 1.15 in the $\mathrm{HbA}_{1 \mathrm{c}}$ value and a $5 \%$ two-sided significance level.

\section{Usual care}

Medical treatment was not part of the intervention. All participants, irrespective of participation in the intervention group or the control group, therefore underwent the same routine check-up at their general practitioner or outpatient clinic in charge of their diabetes care. This usually involved four physician visits per year. Biochemical tests and examinations were usually performed during the visits in accordance with national diabetes guidelines. Individual counselling and recommendations based on the results of the examinations, biochemical tests and their self-monitoring of blood glucose was given. Renewal of prescribed medication and test strips for blood glucose monitoring were also given at these check-ups. Patients could be referred for individual counselling in change of diet, physical activity, smoking habits and alcohol abuse if required by their usual healthcare provider.

\section{Research intervention}

The theoretical approach of the intervention was based on self-efficacy theory and MI spirit. Perceived self-efficacy is defined as people's beliefs about their capabilities of producing designated levels of performance exercising influence over events that affect their lives [25]. MI was used as a method to facilitate this process. MI is a directive counselling style for eliciting behaviour change by helping patients to explore and resolve ambivalence [26, 27].

In addition to usual care, patients in the intervention group received a 1 year MI programme consisting of five individual counselling sessions lasting approximately 45 min and offered at 1, 3, 6, 9 and 12 months. Each participant in the intervention group had a healthcare professional assigned to them who was trained in MI. The style of the interview was: (1) seeking to understand the person's frame of reference; (2) expressing acceptance and affirmation; (3) eliciting and selectively reinforcing the client's own self-motivational statements of problem recognition, concern, desire and intention to change, and ability to change; (4) exploring the client's degree of readiness to change; and (5) affirming the client's freedom of choice and self-direction. The role of exploring readiness to change was that this was used as a component of the therapeutic process and not an outcome. Each session followed a semi-structured interview format of MI, especially developed for this intervention programme. Participants brought up any problematic issues related to diabetes self-care during sessions. The participants in the intervention group could be referred by the healthcare professional to individual counselling in changes of diet, a smoking cessation programme, counselling in alcohol abuse and an exercise programme, as they required.

Education of the healthcare professionals prior to the intervention

Three diabetes specialist nurses, two dietitians, one physiotherapist and one psychologist were educated to carry out MI. They were all coached by a MI trainer from the Motivational Interviewing Network of Trainers in the Nordic countries. The course comprised a 5 day theoretical introduction to strategies in MI. The course was followed by three practical coaching sessions every 3 months for 18 months. The theoretical and practical part of the education included training in the key elements of MI, which is generally facilitating through eliciting change talk and exploring ambivalence about behavioural change, while trying to examine discrepancies between the individual's current behaviour and core values or personal goals. The healthcare professionals were introduced to the MI method including reflective listening and acknowledgement to allow them to be able to clarify the patient's goals and concerns and elicit reasons for change in the patient's own words. The role of the healthcare professionals was to coach and support the patient in discovering and developing his/her own resources for change and management at the patient's request.

After the 5-day course, the healthcare professionals were individually supervised by the MI trainer in ten real patient situations for 1 year. The supervision included videotaping and evaluation inspired by the Motivational Interviewing Treatment Integrity (MITI) coding system (T. B. Moyers, T. Martin, J. K. Manuel, W. R. Miller, D. Ernst, 2007; 
available to trainers and members of the Motivational Interviewing Network of Trainers [MINT]). The MITI coding system is divided into a global rating and behavioural counts. The global rating is a five-point Likert scale, where 1 indicates low competence in MI and 5 indicates high competence in MI. The behaviour counts reveal MI behaviour in proportion to all behaviour, where a high percentage indicates a high competence in MI.

\section{Measurements}

Questionnaires Competence of diabetes self-management was assessed by validated questionnaires translated into a Danish version in accordance with recommendations [24]. The Problem Areas in Diabetes Scale (PAID) was used to measure diabetes-related distress reported by the participants. This 20-item questionnaire assesses a wide range of feelings related to living with diabetes and diabetes treatment $[28,29]$. Each item can be rated on a five point Likert scale ranging from 0 (not a problem) to 4 ('a serious problem'). When transforming PAID scores into a $0-100$ scale, all item scores are summed and multiplied by 1.25 , which results in an overall PAID score with higher scores indicating greater emotional distress [30, 31]. High PAID scores are associated with low self-reported adherence [29]. The Perceived Competence for Diabetes Scale (PCDS) was used to measure competence at carrying out the diabetes treatment regime. This is a five item questionnaire assessing the degree to which participants feel confident about dealing with diabetes $[32,33]$. Each item can be rated on a seven point Likert scale ranging from 1 ('not true at all') to 7 ('very true'). The score on the PCDS is calculated by averaging the responses on the five items. The minimum average score is the one equalling the lowest possible perceived competence in dealing with diabetes and the maximum average score is 7 , equalling the highest possible perceived competence in dealing with diabetes.

Laboratory measurements One laboratory analysed all the blood samples. Glycaemic control was assessed using $\mathrm{HbA}_{1 \mathrm{c}}$, which was measured by a high-performance liquid chromatography-based ion exchanged procedure (Tosho Alc 2.2, Tokyo, Japan). The reference range was $4.3-6.3 \%$. Total cholesterol, HDL cholesterol and triacylglycerol levels were measured in serum by enzymatic methods (Boehringer Mannheim Diagnostica, Mannheim, Germany). LDLcholesterol was calculated by Friedewald's equation [34].

Clinical measurements Both height and weight were measured without shoes. Weight was measured without accessories, i.e. wallet, keys, mobile phone. Waist circumference was measured with a measuring tape directly on the individual's skin. Restrictive garments and clothing were removed. The tape was placed at the uppermost border of the iliac crest horizontal to the floor. Measurement was made at the end of a normal expiration. Blood pressure was measured by the auscultatory method with use of a stethoscope and a sphygmomanometer. An inflatable cuff was placed around the upper left arm, at the same vertical height as the heart. Measurement was made at rest in a sitting position.

Statistical analysis

For data analyses, SPSS (version 18, Chicago, IL, USA) for Windows and STATA (version 11, College Station, TX, USA) were used.

The baseline values are reported as means $\pm \mathrm{SD}$ or $n(\%)$. On the basis of an intention to treat analysis, a mixed effects regression model with random intercept was used to compare primary and secondary outcomes at 12 and 24 months between the intervention and control groups, where treatment was taken as the explanatory variable and the baseline value as a covariate. Further, each outcome was adjusted for the covariates, age, sex, type of diabetes, level of education, $\mathrm{HbA}_{1 \mathrm{c}}$ level at baseline, and healthcare professionals delivering the intervention. A random intercept was included in order to account for possible withinindividual dependence due to repeated measurements. In the same fashion, a random intercept was included to account for cluster effects due to the healthcare professionals. Results are presented as means $(95 \% \mathrm{CI})$. A $p$ value of $<0.05$ was regarded as statistically significant.

\section{Research ethics}

The study design was approved by the Regional Scientific Ethics Committee of Southern Denmark (project-ID: VF20050131) and the study was reported to the Danish Data Protection Agency. All patients were informed about the aim of the study and were included in the study after informed consent. The study was performed in accordance with the Declaration of Helsinki.

\section{Results}

Baseline data

In the period between December 2005 and June 2009, 469 patients attended the diabetes education programme at the diabetes clinic. Some 115 patients declined to participate in the trial and five patients did not meet the inclusion criteria. The reasons for declining were mainly lack of time or lack of energy to complete the trial. Of the 120 non-participants, 62 were women and 56 were men. The distribution of sex 
was comparable in the non-participant group and the eligible group of patients. The mean age in the nonparticipant group was $59.1 \pm 11.8$ years. This was significantly higher $(p=0.040)$ than the age of those who participated in the trial, where the total mean age was $56.4 \pm 12.1$ years. The duration of diabetes was $7.1 \pm$ 10.0 years in the non-participant group and $4.7 \pm 6.7$ years in total among the participants. This difference was significant $(p=0.008)$. No difference was found between the non-participant patients and the eligible patients with regard to weight, blood pressure, $\mathrm{HbA}_{1 \mathrm{c}}$ and lipid profile.

Of the 349 eligible patients, 173 patients were randomised to the intervention group and 176 to the control group. During the 2 year follow-up period, 51 participants (15\%) dropped out, of whom 28 had been allocated to the intervention group and 23 to the control group (Fig. 1). The baseline characteristics and health status of both groups were similar (Table 1). We found no difference in the characteristics of dropout participants compared with those who remained in the study, except for the mean age, where the dropouts were younger than the intervention group (mean difference 4.50 years, $p=0.035$ ).

\section{Intervention}

In the intervention group, the average visits per patient were 4.6 with an average time of 34 min per session during the 1 year intervention programme. In the intervention group, $85 \%$ completed the full intervention programme with the five sessions. The last $15 \%$ in the intervention group had between one and three sessions.

In the intervention group, $17 \%$ were referred to individual counselling in change of diet. The mean numbers of visit per patient were 2.0 (minimum one and maximum five visits). Some $25 \%$ in the intervention group were referred to an exercise programme. The mean numbers of visits per patient were 5.7 (minimum one and maximum 50 visits). Of the patients who participated in dietary counselling and the exercise programme, $15 \%$ received both therapies. Seven per cent in the intervention group participated in individual counselling on smoking cessation. The mean number of visits per patient was 4.9 (minimum 2 and maximum 10 visits). Finally, 3\% of the patients in the intervention group were referred to individual counselling in change of alcohol use. No monitoring in the control group was done.

The global rating scores in the MITI coding of the videotapes were between 4 and 5 points. The behaviour counts showed $80-100 \%$ MI adherent behaviour in proportion to the total behaviour, $76-83 \%$ of open questions in proportion to all questions asked, 36-42\% of complex reflections in proportion to all reflections made and the reflection to question ratio was between 0.8 and 1.8.

\section{Random effects analysis}

When using the baseline value as covariate there were no significant differences in change in score between the two

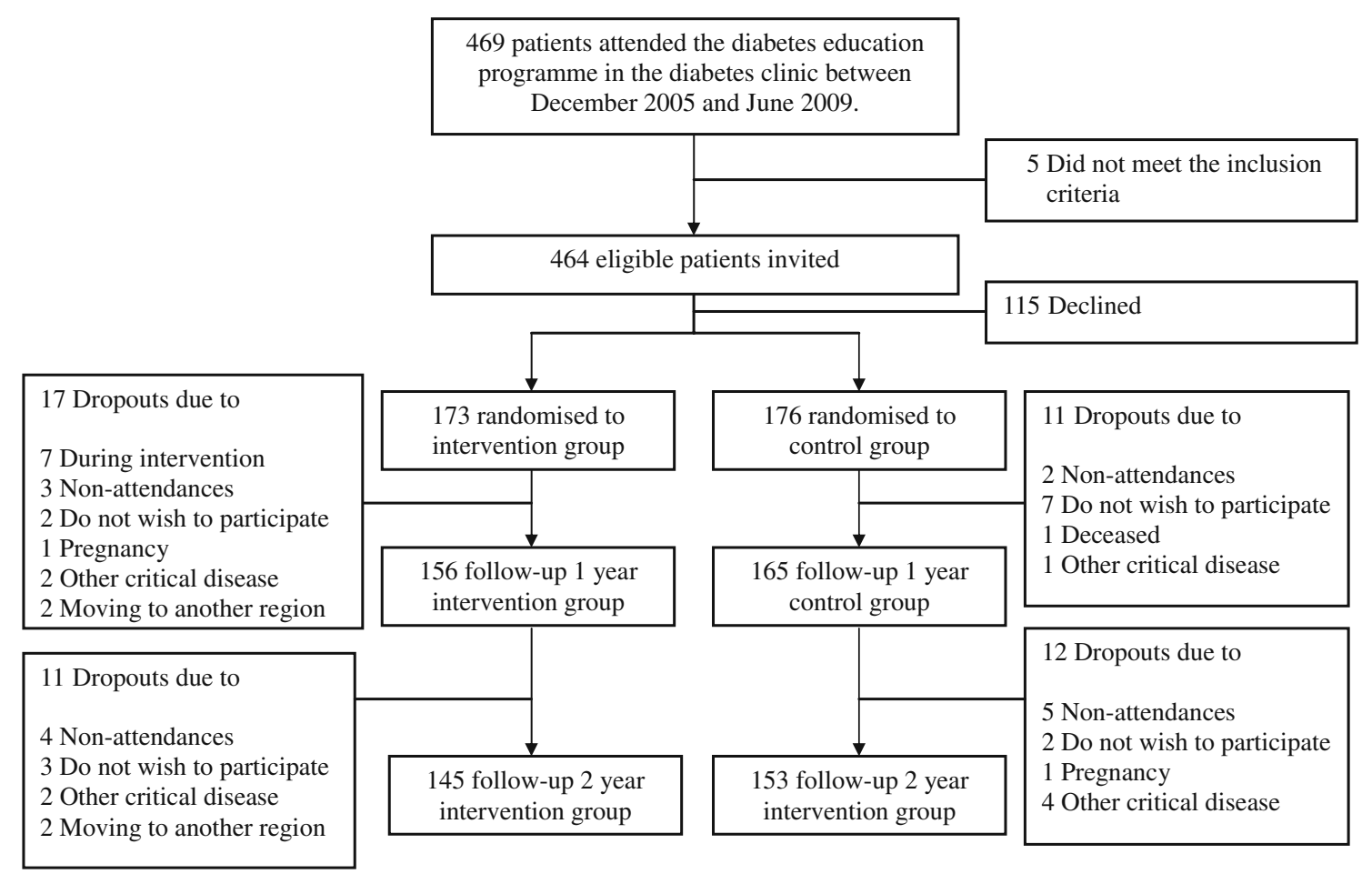

Fig. 1 Flow diagram of inclusion of the study population 
Table 1 Characteristics of the patients at baseline

\begin{tabular}{|c|c|c|}
\hline Variable & Intervention $(n=173)$ & Control $(n=176)$ \\
\hline \multicolumn{3}{|l|}{ Sex } \\
\hline Male & $90(52)$ & $86(49)$ \\
\hline Female & $83(48)$ & $90(51)$ \\
\hline Age (years) & $57.1 \pm 12.6$ & $55.8 \pm 11.6$ \\
\hline Diabetes duration (years) & $4.7 \pm 6.9$ & $4.7 \pm 6.5$ \\
\hline \multicolumn{3}{|l|}{ Type of diabetes } \\
\hline Type 1 & $40(23)$ & $36(21)$ \\
\hline Type 2 & $133(77)$ & $140(79)$ \\
\hline Diagnosed retinopathy & $25(15)$ & $20(11)$ \\
\hline \multicolumn{3}{|l|}{ Educational level $^{\mathrm{a}}$} \\
\hline$\leq$ Middle school & $122(70)$ & $120(68)$ \\
\hline$\geq$ High school & $51(30)$ & $56(32)$ \\
\hline \multicolumn{3}{|l|}{ Connection to the labour market } \\
\hline Transfer payment & $109(63)$ & $106(60)$ \\
\hline Employed/self-employed & $64(37)$ & $70(40)$ \\
\hline \multicolumn{3}{|l|}{ Civil status } \\
\hline Live alone & $55(32)$ & $47(27)$ \\
\hline Cohabiting & $118(68)$ & $129(73)$ \\
\hline Weight (kg) & $89 \pm 18$ & $90 \pm 19$ \\
\hline Body mass index $\left(\mathrm{kg} / \mathrm{m}^{2}\right)$ & $30.8 \pm 5.8$ & $31.1 \pm 6.3$ \\
\hline Waist circumference $(\mathrm{cm})$ & $102 \pm 15$ & $102 \pm 15$ \\
\hline $\mathrm{HbA}_{1 \mathrm{c}}(\%)$ & $7.0 \pm 1.2$ & $7.0 \pm 1.2$ \\
\hline \multicolumn{3}{|l|}{ Blood pressure (mmHg) } \\
\hline Systolic & $131.9 \pm 16.7$ & $132.5 \pm 17.1$ \\
\hline Diastolic & $75.4 \pm 10.4$ & $76.3 \pm 9.7$ \\
\hline \multicolumn{3}{|l|}{ Cholesterol (mmol/l) } \\
\hline Total & $4.4 \pm 1.1$ & $4.5 \pm 1.0$ \\
\hline LDL & $2.3 \pm 1.0$ & $2.3 \pm 0.9$ \\
\hline HDL & $1.4 \pm 0.4$ & $1.4 \pm 0.5$ \\
\hline Triacylglycerol & $1.6 \pm 1.1$ & $1.9 \pm 1.4$ \\
\hline PAID & $20.0 \pm 17.7$ & $19.6 \pm 16.3$ \\
\hline PCDS & $6.3 \pm 1.0$ & $6.1 \pm 1.1$ \\
\hline \multicolumn{3}{|l|}{ Hypoglycaemic treatment } \\
\hline Insulin & $47(27)$ & $52(30)$ \\
\hline OHA & $80(46)$ & $74(42)$ \\
\hline Insulin and $\mathrm{OHA}$ & $14(8)$ & $21(12)$ \\
\hline Antihypertensive treatment & $104(60)$ & $109(62)$ \\
\hline Cholesterol-lowering treatment & $107(62)$ & $119(68)$ \\
\hline
\end{tabular}

Data are mean \pm SD or $n(\%)$

${ }^{\mathrm{a}}$ Middle school is between seventh and ninth grade. High school is ninth to twelfth grade intervention and control group at the 24 month follow-up (Table 2). The patients in the intervention group showed significantly higher levels of perceived competence in dealing with diabetes compared with the control group ( $\Delta$ mean change score $=-0.387, p=0.002) 12$ months post intervention.

We found no statistically significant effect between the healthcare professionals delivering the intervention.

Similar changes in medical treatment over time were found in the intervention and control group as regards insulin, oral hypoglycaemic agents (OHAs), antihyperten( $\Delta$ mean change score $=-0.006, p=0.995)$ between the 
Table 2 Changes in primary and secondary outcome measures over 12 and 24 months in intervention group and control group

\begin{tabular}{|c|c|c|c|c|c|c|c|}
\hline \multirow[t]{2}{*}{ Measure } & \multirow{2}{*}{$\begin{array}{l}\text { Unadjusted mean } \\
\text { scores } \pm \mathrm{SD} \\
\text { Baseline }\end{array}$} & \multicolumn{2}{|c|}{ Adjusted mean scores $(95 \% \mathrm{CI})$} & \multicolumn{4}{|c|}{ Analysis results ${ }^{\mathrm{b}}$} \\
\hline & & 12 months & 24 months & $\begin{array}{l}\Delta \mathrm{Mean}^{\mathrm{a}} \\
12 \text { months }\end{array}$ & $p_{12 \text { months }}$ & $\begin{array}{l}\Delta \text { Mean }^{\mathrm{a}} \\
24 \text { months }\end{array}$ & $p_{24 \text { months }}$ \\
\hline \multicolumn{8}{|l|}{$\mathrm{HbA}_{1 \mathrm{c}}(\%)$} \\
\hline Intervention & $7.02 \pm 1.20$ & $6.93(6.80-7.06)$ & $7.16(7.01-7.31)$ & 0.029 & 0.757 & 0.131 & 0.221 \\
\hline Control & $7.03 \pm 1.16$ & $6.96(6.83-7.08)$ & $7.29(7.15-7.44)$ & & & & \\
\hline \multicolumn{8}{|c|}{ Total cholesterol (mmol/l) } \\
\hline Intervention & $4.43 \pm 1.08$ & $4.27(4.16-4.39)$ & $4.37(4.24-4.51)$ & 0.073 & 0.375 & 0.154 & 0.110 \\
\hline Control & $4.54 \pm 1.01$ & $4.41(4.30-4.52)$ & $4.59(4.46-4.72)$ & & & & \\
\hline \multicolumn{8}{|c|}{ LDL-cholesterol (mmol/1) } \\
\hline Intervention & $2.35 \pm 0.99$ & $2.31(2.21-2.40)$ & $2.43(2.32-2.54)$ & 0.008 & 0.908 & 0.001 & 0.981 \\
\hline Control & $2.30 \pm 0.86$ & $2.32(2.32-2.42)$ & $2.44(2.33-2.55)$ & & & & \\
\hline \multicolumn{8}{|l|}{ PAID } \\
\hline Intervention & $20.0 \pm 17.7$ & $18.5(16.3-20.6)$ & $19.5(17.6-21.4)$ & 1.522 & 0.321 & -1.793 & 0.191 \\
\hline Control & $19.6 \pm 16.3$ & $20.2(18.1-22.3)$ & $17.9(16.1-19.8)$ & & & & \\
\hline \multicolumn{8}{|l|}{ PCDS } \\
\hline Intervention & $6.27 \pm 1.05$ & $6.25(6.07-6.42)$ & $6.03(5.84-6.22)$ & -0.387 & 0.002 & 0.017 & 0.903 \\
\hline Control & $6.18 \pm 1.11$ & $5.82(5.65-5.98)$ & $6.00(5.81-6.19)$ & & & & \\
\hline \multicolumn{8}{|l|}{ Weight (kg) } \\
\hline Intervention & $89.7 \pm 17.7$ & $89.3(88.5-90.1)$ & $90.8(89.9-91.6)$ & 0.588 & 0.210 & 0.664 & 0.291 \\
\hline Control & $89.6 \pm 18.3$ & $90.3(89.5-91.0)$ & $91.8(90.9-92.6)$ & & & & \\
\hline \multicolumn{8}{|c|}{ Waist circumference $(\mathrm{cm})$} \\
\hline Intervention & $102.2 \pm 14.6$ & $102.8(102.0-103.6)$ & $102.4(100.6-104.3)$ & 0.230 & 0.690 & 1.366 & 0.297 \\
\hline Control & $102.4 \pm 15.1$ & $102.9(102.1-103.7)$ & $103.7(101.9-105.5)$ & & & & \\
\hline \multicolumn{8}{|c|}{ Systolic BP (mmHg) } \\
\hline Intervention & $131.9 \pm 16.7$ & $135.0(132.6-136.9)$ & $133.3(131.1-135.5)$ & -2.33 & 0.102 & -0.145 & 0.927 \\
\hline Control & $132.5 \pm 17.1$ & $132.6(130.7-134.6)$ & $133.1(131.0-135.2)$ & & & & \\
\hline \multicolumn{8}{|c|}{ Diastolic BP (mmHg) } \\
\hline Intervention & $75.4 \pm 10.5$ & $78.9(77.6-80.2)$ & $77.1(75.8-78.4)$ & -1.040 & 0.260 & -0.006 & 0.995 \\
\hline Control & $76.3 \pm 9.7$ & $78.1(76.9-79.4)$ & $77.3(76.1-78.6)$ & & & & \\
\hline
\end{tabular}

${ }^{\mathrm{a}}$ The difference in mean change score between groups ([Int $\left.\left.-\mathrm{Int}_{1}\right]-\left[\mathrm{Con}_{0}-\mathrm{Con}_{1}\right]\right)$

${ }^{\mathrm{b}}$ Comparison between the two groups for primary and secondary outcomes was performed by a mixed effects regression model with random intercept, adjusting for baseline values and age, sex, type of diabetes, level of education and $\mathrm{HbA}_{1 \mathrm{c}}$ level at baseline with a random intercept

sive agents, cholesterol-lowering agents, anticoagulants and steroids (electronic supplementary material [ESM] Table 1).

\section{Discussion}

The main findings of this 1 year study were that patients with diabetes participating in a MI programme did not improve glycaemic control or competence of selfmanagement in the intervention group compared with the control group. We found that the intervention maintained patients' perceived competence in dealing with diabetes compared with the control group just after the intervention. However, this difference between the groups disappeared at the 24 month follow-up.
The lack of effect on $\mathrm{HbA}_{1 \mathrm{c}}$, lipid profile and other clinical outcomes such as weight and waist circumference might indicate that the patients in the intervention group did not change behaviour towards a higher degree of diabetes self-care including healthy diet and more physical activity. These findings are supported by the fact that we found no evidence that MI improved competence of selfmanagement over time. This might indicate that it takes more time before the effectiveness of MI on patients' cognition could be seen in desirable behavioural changes in diabetes self-management [35].

Previous meta-analyses have revealed that behavioural and educational interventions in diabetes have produced modest short-term improvements in glycaemic control. There was a tendency to non-significant improvements in 
glycated haemoglobin in the included studies where the mean $\mathrm{HbA}_{1 \mathrm{c}}$ values were less than $8.5 \%$ at baseline [4-6, 36]. A tendency to a reduced effect on glycaemic control was found in studies where the duration of diabetes was above 9 months [6]. Our results correspond with these findings. Essentially, MI might not improve glycaemic control in patients who have a relatively lower $\mathrm{HbA}_{1 \mathrm{c}}$ and longer duration of diabetes, especially when general practitioners or diabetologists see them regularly.

It appears from the mean PAID result at baseline that patients entering into the study had a relatively low level of diabetes-related distress. This is similar to what is found in unselected outpatient groups [31]. The fact that the patients had participated in an education programme before entering into the study might be the reason for such a relatively low level of diabetes-related distress at baseline, which might be reflected in the follow-up measurement. The mean PCDS results at baseline were close to the maximum score in both the intervention and the control group, which might also be explained by the fact that the patients had received education in diabetes before entering the study. Patients in the intervention group scored significantly better in perceived competence in dealing with diabetes just after the end of the intervention, compared with the control group. This might indicate that the intervention helped patients feel more competent in managing their diabetes. However, the instrument has not been developed directly to be used in clinical practice and the interpretation of how changes in mean PCDS score have an influence on patients' diabetes self-management is not clear. Moreover, the ceiling effect occurred as a high proportion of participants in the study had maximum scores in PCDS at baseline.

This study provided insight into the effect of a behavioural and educational intervention. Implementing MI as a new method in diabetes care required a shift in the healthcare professionals' role as well as practical training. Previous studies have shown that several barriers have to be overcome before a new method can be applied [37-39]. To accommodate these barriers, supervision and practical coaching sessions were held after the theoretical introduction to MI. It is a strength of this study that there has been supervision, which included videotaping and evaluation by the MITI coding system, both to facilitate the use of MI and to ensure that the method was used correctly in the intervention. The evaluation using MITI coding demonstrated a high competency in using MI among the healthcare providers in the study.

\section{Limitations}

The power calculation showed that 352 patients were needed to show a $0.4 \%$ difference in $\mathrm{HbA}_{1 \mathrm{c}}$. Unfortunately, several patients declined participation, which resulted in lower statistical power than planned. The fact that we failed to achieve our recruitment target might have hindered us statistically in detecting a possible intervention effect and thus we risked overlooking a real difference between intervention and control group. Furthermore, we cannot totally exclude the risk of contamination bias, which in this case could occur if patients in the control group changed their behaviours after interacting with patients in the intervention group, or if the healthcare professionals assigned to deliver the intervention also treated patients in the control group coming to the diabetes clinic for routine care. Contamination bias might diminish the magnitude of the difference between the intervention and usual care. Most of the patients entering this study, however, went to their general practitioner for routine care, which might minimise the risk of contamination bias. Nevertheless, use of a cluster design might have minimised the possibility of contamination bias even more.

\section{Significance}

With this randomised controlled trial we were unable to provide evidence that MI should be considered for adoption in routine diabetes care. When implementing a new approach in diabetes treatment, we have to consider who are most likely to benefit from this kind of intervention. Considering the group of patients who declined to participate in our trial, it was evident that they were older and had had diabetes for a longer time period than those who participated in the trial. This could indicate that intensive interventions might be less attractive and manageable for the older population with diabetes. We also might speculate that behavioural interventions including MI are only effective for problem behaviours if these are associated with poor glycaemic control.

In our trial, no improvements were found in cardiovascular risk profiles, whereas such improvements are often found in pharmacological studies $[40,41]$ with consequent improvements in mortality and morbidity. We did not intervene in medical treatment and it is therefore reasonable to assume that it was the intervention based on MI that improved the patient's perceived competence in diabetes post intervention. This might indicate that behavioural and educational intervention adds another dimension to diabetes care, compared with medical treatment. Therefore, the effectiveness of behavioural and educational intervention given in addition to usual care might be best assessed with psychological rather than biochemical variables in patients with $\mathrm{HbA}_{1 \mathrm{c}}$ levels less than $8 \%$. This is substantiated by a previous review that pointed out the difficulty in assessing the unique contribution of diabetes patient education to diabetes outcomes [42]. Another review recommended that the evaluation of diabetes patient education, including behavioural and educational intervention, is concentrated on the goal of optimal adjustment to living with diabetes, as 
this kind of treatment is believed to play a discernable role in knowledge, self-determination, self-management and psychological adjustment [43].

MI proved to be a good power-generating tool for the staff members, who need both knowledge and practical communication tools to talk to patients about difficult topics. Based on this knowledge, the professions involved in clinical practice can be advanced by a more qualified reinforcement of initiatives regarding behavioural changes concerning lifestyle issues in a clinical setting. To succeed with this, it is necessary to focus on the implementation process and continuously follow up on this to achieve this goal.

Finally, we were unable to demonstrate any benefit of MI over and above usual care in patients with wellregulated diabetes and newly completing a diabetes education programme.

Acknowledgements The authors thank the study patients for their participation in the study. Thanks to the team members at the Diabetes Clinic Department of Endocrinology L. Sjöberg, I. Kamp, E. Romanczuk, I. Eggertsen, T. Flemming Larsen, G. Kramer and B. Nielsen for their invaluable contributions to the study. Thanks also to other staff at the Diabetes Clinic Department of Endocrinology for co-operation and assistance throughout the trial. Thanks also to L. Stark at the Research Unit of General Practice for language editing of the manuscript. This study was financially supported by the National Board of Health, Funen County, Danish Association of Diabetes, Odense University Hospital, University of Southern Denmark and TRYG Fonden.

Duality of interest The authors declare that there is no duality of interest associated with this manuscript.

\section{References}

1. Funnell MM, Anderson RM (2004) Empowerment and selfmanagement of diabetes. Clin Diab 22:123-127

2. Peyrot M, Rubin RR, Lauritzen T, Snoek FJ, Matthews DR, Skovlund SE (2005) Psychosocial problems and barriers to improved diabetes management: results of the Cross-National Diabetes Attitudes, Wishes and Needs (DAWN) Study. Diabet Med 22:1379-1385

3. Loveman E, Royle P, Waugh N (2003) Specialist nurses in diabetes mellitus. Cochrane Database Syst Rev, Issue 2, Art no.: CD003286. doi:10.1002/14651858.CD003286

4. Gary TL, Genkinger JM, Guallar E, Peyrot M, Brancati FL (2003) Meta-analysis of randomized educational and behavioral interventions in type 2 diabetes. Diab Educ 29:488-501

5. Ismail K, Winkley K, Rabe-Hesketh S (2004) Systematic review and meta-analysis of randomised controlled trials of psychological interventions to improve glycaemic control in patients with type 2 diabetes. Lancet 363:1589-1597

6. Minet L, Moller S, Vach W, Wagner L, Henriksen JE (2010) Mediating the effect of self-care management intervention in type 2 diabetes: a meta-analysis of 47 randomised controlled trials. Patient Educ Couns 80:29-41

7. Norris SL, Engelgau MM, Narayan KM (2001) Effectiveness of self-management training in type 2 diabetes: a systematic review of randomized controlled trials. Diab Care 24:561-587
8. Shojania KG, Ranji SR, McDonald KM, Grimshaw JM, Sundaram V, Rushakoff RJ et al (2006) Effects of quality improvement strategies for type 2 diabetes on glycemic control: a metaregression analysis. JAMA 296:427-440

9. Deakin T, McShane CE, Cade JE, Williams RD (2005) Group based training for self-management strategies in people with type 2 diabetes mellitus. Cochrane Database Syst Rev, Issue 2, Art no.: CD003417. doi:10.1002/14651858.CD003417.pub2

10. Duke SA, Colagiuri S, Colagiuri R (2009) Individual patient education for people with type 2 diabetes mellitus. Cochrane Database Syst Rev, Issue 1, Art no.: CD005268. doi:10.1002/14651858.CD005268.pub2

11. Swedish Council on Technology Assessment in Health Care (2009) Patient Education in Diabetes - a systematic review. Swedish Council on Technology Assessment in Health Care, Sweden

12. Rollnick S, Miller WR (2008) Motivational Interviewing in Health Care-helping patients change behaviour. The Guilford Press, New York

13. Martins RK, McNeil DW (2009) Review of motivational interviewing in promoting health behaviors. Clin Psychol Rev 29:283-293

14. Brug J, Spikmans F, Aartsen C, Breedveld B, Bes R, Fereira I (2007) Training dietitians in basic motivational interviewing skills results in changes in their counseling style and in lower saturated fat intakes in their patients. J Nutr Educ Behav 39:8-12

15. Channon S, Smith VJ, Gregory JW (2003) A pilot study of motivational interviewing in adolescents with diabetes. Arch Dis Child 88:680-683

16. Channon SJ, Huws-Thomas MV, Rollnick S et al (2007) A multicenter randomized controlled trial of motivational interviewing in teenagers with diabetes. Diab Care 30:1390-1395

17. Ismail K, Thomas SM, Maissi E et al (2008) Motivational enhancement therapy with and without cognitive behavior therapy to treat type 1 diabetes: a randomized trial. Ann Intern Med 149:708-719

18. Viner RM, Christie D, Taylor V, Hey S (2003) Motivational/ solution-focused intervention improves $\mathrm{HbA1c}$ in adolescents with type 1 diabetes: a pilot study. Diabet Med 20:739-742

19. West DS, DiLillo V, Bursac Z, Gore SA, Greene PG (2007) Motivational interviewing improves weight loss in women with type 2 diabetes. Diab Care 30:1081-1087

20. Clark M, Hampson SE (2001) Implementing a psychological intervention to improve lifestyle self-management in patients with type 2 diabetes. Patient Educ Couns 42:247-256

21. Knight KM, Bundy C, Morris R et al (2003) The effect of group motivational interviewing and externalizing conversations for adolescents with type 1 diabetes. Psychol Health Med 8:149-157

22. Smith DE, Heckemeyer CM, Kratt PP, Mason DA (1997) Motivational interviewing to improve adherence to a behavioral weight-control program for older obese women with NIDDM. A pilot study. Diabetes Care 20:52-54

23. Knight KM, McGowan L, Dickens C, Bundy C (2006) A systematic review of motivational interviewing in physical health care settings. Br J Health Psychol 11:319-332

24. Zoffmann V, Lauritzen T (2006) Guided self-determination improves life skills with type 1 diabetes and $\mathrm{A} 1 \mathrm{C}$ in randomized controlled trial. Patient Educ Couns 64:78-86

25. Bandura A (1997) Self-efficacy. The exercise of control. W. H. Freeman and Company, New York

26. Miller WR, Rollnick S (2002) Motivational interviewing: preparing people for change, 2nd edn. Guilford Press, New York

27. Miller WR, Rollnick S (2009) Ten things that motivational interviewing is not. Behav Cogn Psychother 37:129-140

28. Polonsky WH, Anderson BJ, Lohrer PA et al (1995) Assessment of diabetes-related distress. Diab Care 18:754-760

29. Welch GW, Jacobson AM, Polonsky WH (1997) The problem areas in diabetes scale. An evaluation of its clinical utility. Diab Care 20:760-766 
30. Snoek FJ, Pouwer F, Welch GW, Polonsky WH (2000) Diabetesrelated emotional distress in Dutch and US diabetic patients: cross-cultural validity of the problem areas in diabetes scale. Diab Care 23:1305-1309

31. Welch G, Weinger K, Anderson B, Polonsky WH (2003) Responsiveness of the problem areas in diabetes (PAID) questionnaire. Diabet Med 20:69-72

32. Williams GC, Freedman ZR, Deci EL (1998) Supporting autonomy to motivate patients with diabetes for glucose control. Diab Care 21:1644-1651

33. Zoffmann V (2004) Guided self-determination. A life skills approach developed in difficult type 1 diabetes. $\mathrm{PhD}$ thesis. Aarhus: Faculty of Health Sciences University of Aarhus

34. Friedewald WT, Levy RI, Fredrickson DS (1972) Estimation of the concentration of low-density lipoprotein cholesterol in plasma, without use of the preparative ultracentrifuge. Clin Chem 18:499 502

35. Rubak S, Sandbaek A, Lauritzen T, Christensen B (2005) Motivational interviewing: a systematic review and meta-analysis. Br J Gen Pract 55:305-312

36. Norris SL, Lau J, Smith SJ, Schmid CH, Engelgau MM (2002) Self-management education for adults with type 2 diabetes: a meta-analysis of the effect on glycemic control. Diab Care 25:1159-1171
37. Adolfsson ET, Smide B, Gregeby E, Fernstrom L, Wikblad K (2004) Implementing empowerment group education in diabetes. Patient Educ Couns 53:319-324

38. Pill R, Rees ME, Stott NC, Rollnick SR (1999) Can nurses learn to let go? issues arising from an intervention designed to improve patients' involvement in their own care. J Adv Nurs 29:1492-1499

39. Woodcock AJ, Kinmonth AL, Campbell MJ, Griffin SJ, Spiegal NM (1999) Diabetes care from diagnosis: effects of training in patient-centred care on beliefs, attitudes and behaviour of primary care professionals. Patient Educ Couns 37:65-79

40. DCCT Research Group (1993) The effect of intensive treatment of diabetes on the development and progression of long-term complications in insulin-dependent diabetes mellitus. The Diabetes Control and Complications Trial Research Group. N Engl J Med 329:977-986

41. UKPDS Group (1998) Intensive blood-glucose control with sulphonylureas or insulin compared with conventional treatment and risk of complications in patients with type 2 diabetes (UKPDS 33). UK Prospective Diabetes Study (UKPDS) Group. Lancet 352:837-853

42. Fain JA, Nettles A, Funnell MM, Charron D (1999) Diabetes patient education research: an integrative literature review. Diab Educ 25:7-15

43. Colagiuri R, Eigenmann CA (2009) A national consensus on outcomes and indicators for diabetes patient education. Diabet Med 26:442-446 